\title{
Lista de Revisores de 2016
}

O Corpo Editorial da Revista Portuguesa de Medicina Geral e Familiar realça o papel dos revisores no sucesso da revista, particularmente, a sua crítica construtiva aos artigos submetidos à revisão por pares. Terminado mais um ano, agradecemos aos revisores o seu profissionalismo, o qual permitiu assegurar o processo editorial durante o ano de 2016.

\section{NOME}

Adriana Rubín

Ana Catarina Conduto

Ana Catarina Faro

Ana Cebolais

Ana Cristina Moreira

Ana Filipe Pinheiro

Ana Gomes

Ana Isabel Custódio

Ana Isabel Silva

Ana Laura Fitas

Ana Luísa Neves

Ana Machado Gomes

Ana Sanches

Ana Silva Rodrigues

Ana Teresa Brito

André Lencastre

Ângela Neves

António Vaz Carneiro

Armando Brito Sá

Bárbara Antunes

Bruno Heleno

Bruno Morrão

Camila Neves

Cândida Mendes

Carla Almeida

Carla Gouveia

Carla Morna

Carla Ponte

Cláudia Vicente

Daniel Pinto

Dilermando Sobral

Dulce Abreu

Edgar Ferreira

Eunice Carrapiço

Fátima Baltazar

Guilherme Mendes

Hélder Aguiar

Helena Beça

Helena Chantre

Helena Lopes

Isabel Crespo

Isabel Pratas

Ivone Gaspar

Joana Cabrita

Joana Costa Gomes

Joana Ferreira
AFILIAÇÃO PROFISSIONAL

Medicina Geral e Familiar

Medicina Geral e Familiar

Pediatria

Medicina Geral e Familiar

Medicina Geral e Familiar

Medicina Geral e Familiar

Medicina Geral e Familiar

Medicina Geral e Familiar

Medicina Geral e Familiar

Pediatria

Medicina Geral e Familiar

Medicina Geral e Familiar

Medicina Geral e Familiar

Medicina Geral e Familiar

Pedagogia

Dermatologia

Medicina Geral e Familiar

Medicina Interna

Medicina Geral e Familiar

Psicologia Clínica

Medicina Geral e Familiar

Medicina Geral e Familiar

Medicina Geral e Familiar

Medicina Geral e Familiar

Medicina Geral e Familiar

Medicina Geral e Familiar

Medicina Geral e Familiar

Medicina Geral e Familiar

Medicina Geral e Familiar

Medicina Geral e Familiar

Medicina Geral e Familiar

Medicina Geral e Familiar

Medicina Geral e Familiar

Medicina Geral e Familiar

Medicina Geral e Familiar

Medicina Geral e Familiar

Medicina Geral e Familiar

Medicina Geral e Familiar

Medicina Geral e Familiar

Medicina Geral e Familiar

Fisiatria

Medicina Geral e Familiar

Medicina Geral e Familiar

Medicina Geral e Familiar

Medicina Geral e Familiar

Medicina Geral e Familiar
NOME

Joana Freire Alves

Joana I. Santos

Joana Neto

João Monteiro

João Sarmento

José António Miranda

José Mendes Nunes

José Ramos

Josefina Marau

Juliana Couto

Leonel Monteiro

Liliana Laranjo

Luís Monteiro

Luísa Carvalho

Luísa Pires Santos

Madalena Sales Luís

Maja Furlan de Brito

Maria Conceição Balsinha

Maria Knoblich

Mariana Martins

Marisa Freire

Miguel Almeida

Miguel Antunes

Milene Fernandes

Mónica Granja

Nélson Brito

Nuno Florêncio

Paula Malvar

Paula Rosa

Paula Silva

Paulo Santos

Pedro Alves

Raquel Braga

Ricardina Barroso

Rita Viegas

Rubina Silva

Rui Lúcio

Rute Cordeiro

Sénia Guerreiro

Soraia Reis

Tiago Baptista

Vanda Proença

Vasco Macias

Vera Costa
AFILIAÇÃO PROFISSIONAL

Medicina Geral e Familiar

Medicina Geral e Familiar

Medicina Geral e Familiar

Medicina Geral e Familiar

Medicina Geral e Familiar

Medicina Geral e Familiar

Medicina Geral e Familiar

Psiquiatria

Medicina Geral e Familiar

Medicina Geral e Familiar

Medicina Geral e Familiar

Medicina Geral e Familiar

Medicina Geral e Familiar

Medicina Geral e Familiar

Medicina Geral e Familiar

Pediatria

Psicologia e Investigação

Medicina Geral e Familiar

Cirurgia Pediátrica

Medicina Geral e Familiar

Medicina Geral e Familiar

Urologia

Ciências Farmacêuticas

Ciências Farmacêuticas e

Investigação

Medicina Geral e Familiar

Medicina Geral e Familiar

Medicina Geral e Familiar

Medicina Geral e Familiar

Pneumologia

Medicina Geral e Familiar

Medicina Geral e Familiar

Medicina Geral e Familiar

Medicina Geral e Familiar

Medicina Geral e Familiar

Medicina Geral e Familiar

Medicina Interna

Urologia

Medicina Geral e Familiar

Medicina Geral e Familiar

Medicina Geral e Familiar

Medicina Geral e Familiar

Medicina Geral e Familiar

Dermatologia

Medicina Geral e Familiar 